\title{
Integrated information support for the production and services on the basis of open technical vocabulary
}

\author{
Vera Cherkina*
}

Moscow State University of Civil Engineering, Yaroslavskoe shosse, 26, Moscow, 129337, Russia

\begin{abstract}
Among the various directions in the development of Russian processes for standardizing products, both military and civilian, taking into account the international system for standardizing the information flow of data on products and technologies, the questions of improving of master data as a material carrier of information. The problem of data quality is payed increased attention, especially in countries of Western Europe, and primarily the United States. Developed and implemented are the corresponding series of international standards - ISO-8000, regulating the structure, syntax, semantics, portability and other attributes of data, and ISO-22745, determining their quality. Both standards were proposed by the US Defense Logistics Agency (DLA).
\end{abstract}

\section{Introduction}

This research is aimed at studying the methodological and organizational problems of professional risk management in construction. Increased attention specifically to data, as a category, often underestimated by Russian experts in the field of standards, caused by the fact that in recent time data have become a new reality, gained "material strength". There was a kind of information revolution, an IT revolution that directly affected the interests of the masses of people around the world. The desire for progress, through the improvement of information flows, has played a negative role. Now the data itself determines our life, and the problem of their quality, i.e. correctness, interpretability, portability, control, redundancy, security, etc., come to the fore. This problem is intensified in the interstate communication, both at the level of standardization specialists and at the level of specific commercial structures. That is why this issue is given increased attention at the federal level.

\section{Methodology}

In the developed European countries, the problem of ensuring the quality of data at the global level, at the level of interstate standards, several organizations are engaged at once. The most official status and at the same time the most impressive results are the ESSMA.

\footnotetext{
Corresponding author: vera.cherkina@mail.ru
} 


\subsection{Ensuring the quality of data at the global level}

The international non-profit association ESSMA was formed in April 1999 with the participation of the United Nations and is currently managing the ISO project 22745 series "Open Technical Dictionaries" and 8000 "Data Quality" within the Technical Committee for Standardization 184 and Subcommittee 4 (TC 184 / SC 4), responsible for the development and maintenance of industrial data. The Russian Federal Agency for Technical Regulation and Metrology (Rosstandart) for many years cooperates with ESSMA and TC ISO 184. As a result, Rosstandart has approved several dozens of national standards based on ISO 22745 and ISO 8000 and this work is actively continuing. The results of master data and ISO 8000-1x0 requirements with service architecture to manage the master data were obtained for understanding in the context of a Big Data project [8-10]. Scientists apply the new approach to combining aspects in order to drive Data Mining techniques to the fields of Massive Open Online Courses (MOOCs) and Open Data extracted from the University of Alicante [11]. The theoretical foundations discussed the new International Organization for Standardization (ISO) standards related to the exchange of master data, such as ISO 8000 family of standards, and also relationship to the ISO 22745-10, -30, and - 40 standards [12-14]. The common aspects in terms of real motivations of Integrated Management Systems (IMS) across regions and companies of different size and sectors reported in the studies with different approaches to integration of IMS (ISO 9001, ISO 14001, OHSAS 18001 and SA 8000) emerged [15-17].

The main information product of the ESSMA Association is the open technical dictionary eOTD (ECCMA Open Technical Dictionary). On the basis of this dictionary, a methodology for describing goods, works, and services is distinguished, differing from other studies in this area, with special attention to the quality of the data [1]. ESSMA's work on eOTD is rooted in the US Federal Cataloging System and the NATO Codification Federal System (FCS). The latter has been in use for more than 50 years, distributed in more than 66 countries and cost developers 5000 man-years, or together with tax deductions and other overheads of more than 5 billion US dollars [2,1]. It is known that the methodology laid down in the ISO series 227458000 serves as a basis for the modernization of the NCS, and in the aspect of its demilitarization [3]. FCS and NCS systems are the basis for the Russian federal product cataloging system for federal state needs by Rosstandart.

\subsection{NATO cataloging system}

Cataloging system by the NATO uses a single (internal, code) language for the procurement and supply of weapons, military equipment, vehicles, consumables, technology and other supplies suitable for computer processing that can be used in all logistic operations. This single language does not depend on national languages: the identification data and the description of the supply subject are stored and exchanged in coded form, and at the output they are formed in one of the 19 national languages of the user countries. In addition, the characteristic feature of the NATO cataloging system is the ability to interact with many other information systems NAICS, HG, UN SPSC, etc., as well as with database management systems such as SAP, Oracle \& Maximo, etc. Naturally one of the the main tasks of cataloging are the management of resources in order to minimize excess supplies of supplies.

In total, the NCS system contains 91 million records, covering about 17 million supplies, which have 50,000 items. The structured list contains 27 thousand of their characteristics with more than 150 thousand values. The number of suppliers and manufacturers is approaching two million. 
On a closer approximation of the two systems. In the meantime, work is being done in both directions, both in the direction of the creation of a Russian vocabulary using the ECSSA methodology [4] with transitional keys to the main operating Russian classifiers OKDP, OKP, TN VED, projected OKPD, and the inclusion of Russian catalog information through membership in eOTD in ESSMA and through the organization of works through specialized commercial organizations $[5,6]$.

\section{Results and discussion}

For the Russian regulatory field, this kind of technical dictionary is a new tool that can greatly simplify the task of codifying and identifying products. The dictionary, in fact, is the link between the product directories on the one hand and the classifiers on the other. The introduction of the dictionary will allow us to gradually abandon the cumbersome classifiers of products, which today perform a dual function: the classifier itself and the inevitably incomplete list of approved product names.

The ESSMA Association defines eOTD as an open state register containing over one million terms and definitions from international, national and industry standards. A Russian-speaking user will most likely enter the phrase "open technical dictionary", or the abbreviation "ESSMA", or the term "eOTD", in the Yandex search line and, after all, get to the website of the ESSMA Association www.eccma.org (Figure 1). Membership in ESSMA allows you to significantly simplify the use of the dictionary. The associate member receives basic support in matters of cataloging, as well as the possibility of obtaining and implementing a corporate business dictionary based on eOTD. Classes, properties, characteristics, representations, units of measurement and other categories of the dictionary are retrieved and displayed in a few seconds by the search software eOTD (the search string is encircled by the red circle in Figure 1). Thus, the term STANDARDIZATION stands for American National Standards Institute as A database transaction involving the standardization of a term entry. The description of technological processes in construction in [18-21] had studied using formal language.

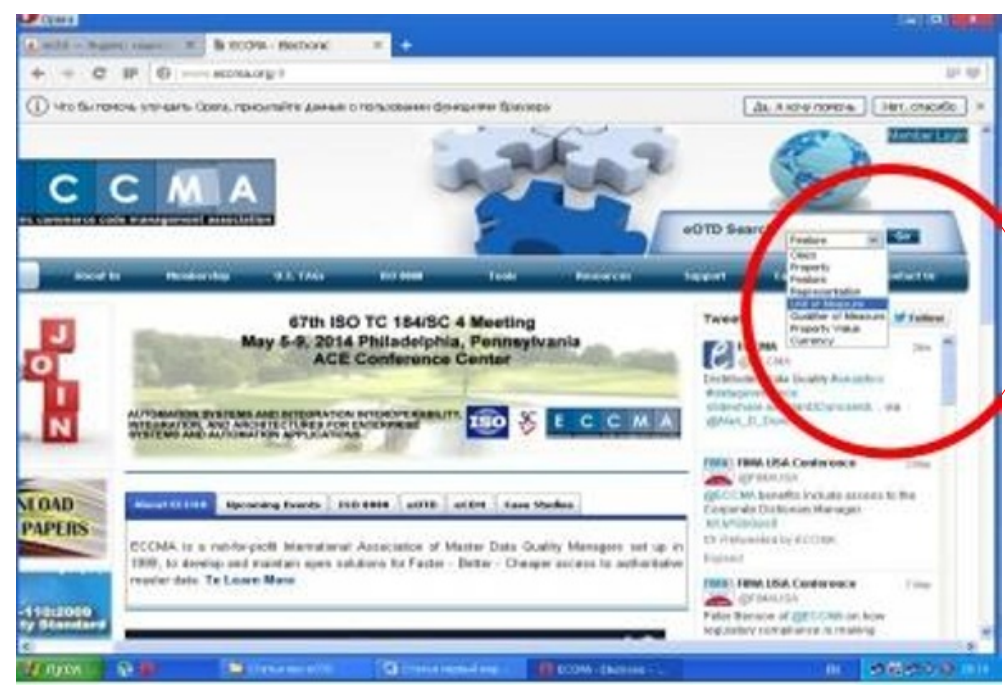

Fig. 1. ESSMA website with eOTD dictionary search engine.

An important component of eOTD is the register of concepts correspondence, 
which allows different groups from different industries to correlate the terminology used. For example, eOTD elegantly solves the famous Anglo-Saxon problem of the differences between the terms "inner diameter" and "bore", meaning the same, by allowing controllers to enter two entries into the dictionary. This process is called public compliance, or public transformation. In practice, it is simpler to use the eOTD identifiers that encode the original information into single-valued, linguistically independent portable data.

\section{Conclusions}

In conclusion, it should be noted that special research in the field of integrated information support for the production, promotion and sale of goods, works, services on the basis of an open technical vocabulary should be accelerated and maintained as much as possible. The question of how to build the Russian cataloging system and its convergence with the European cataloging system is still open. In practice, the described vocabulary system should be implemented as the basic element is an open technical dictionary. Whether it will be its own Russian version of eOTD, compatible with the western original, or integration into eOTD, time will tell. In favor of the second version, the fact that the North Atlantic Alliance adopted the decision to transfer Russia to the second, the highest level in the NATO cataloging system, is evidence of the second version.

\section{References}

1. Better Quality Data - Better Quality Information, Joint Bulletin of the Federal Agency for Technical Regulation and Metrology, ESSMA and Federal Center for Cataloging (2018)

2. On-line: http:// www.freshinternational.com

3. Memorandum of agreement between the Association for the Management of E- Commerce Codes (ESSMA) and the Joint Committee of NATO (AC / 135) (2010)

4. A. Kartashev., S. Filippov, Information Systems, 4 (2009)

5. On-line: http://www.pilogrus.ru

6. On-line: http:// www.myshared.ru

7. Y. Karnaushkin, The world of standards, 7 (38) (2009)

8. B. Rivas, J. Merino, I. Caballero, M. Serrano, Computer Standards \& Interfaces. 54, Part 2, 4 (2017)

9. N. Golov, L. Rönnbäck, Computer Standards \& Interfaces. 54, 2 (2017)

10. D. Quiñones, C. Rusu, Computer Standards \& Interfaces. 53 (2017)

11. J. Peral, A. Maté, M. Marco, Computer Standards \& Interfaces. 50 (2017)

12. J. R. Talburt, Y. Zhou, Entity Information Life Cycle for Big Data (2015)

13. M. Matsuda, S. Matsumoto, N. Noyama, Y. Sudo, F. Kimura, Procedia CIRP, 57 (2016)

14. A. Carretero, F. Gualo, I. Caballero, M. Piattini, Computer Standards \& Interfaces, 54, 3 (2017)

15. R. Salomone. Integrated management systems: experiences in Italian organizations. Journal of Cleaner Production, 16, 16 (2008).

16. T. Jørgensen, A. Remmen, M. D. Mellado, Journal of Cleaner Production, 14, 8 (2006)

17. S. Karapetrovic, M. Casadesús, Journal of Cleaner Production, 17, 5 (2009)

18. E. Korol, P. Kagan, T. Barabanova, I. Bunkina, International Journal of Applied Engineering Research, 11, 3 (2016) 
19. V.Borkovskaya, E. Degaev, I. Burkova, MATEC Web of Conference 2018, Vol. 193 (2018)

20. V.Borkovskaya, D. Passmore, MATEC Web of Conference 2018, Vol. 193 (2018)

21. V. Borkovskaya, W. Bardenwerper, R. Roe, IOP Conf. Series: Materials Science and Engineering, 365 (2018) 